\title{
PERFORMANCE EVALUATION OF THE VEGETABLE TRADING CENTER IN LANTAPAN, BUKIDNON, PHILIPPINES
}

\author{
Karen Debbie J. Cosrojas \\ Department of Agricultural Economics, College of Agriculture/ Central \\ Mindanao University, Philippines \\ corresponding author: debbiecosrojas@gmail.com
}

\begin{abstract}
This paper evaluated the performance of the project: "Farmer Cluster-Managed Bagsakan (trading center) Model in Lantapan, Bukidnon". It used the CIPP and OECD-DAC evaluation frameworks to make sense of the data. The said project envisioned to operate a farmer-cluster managed bagsakan center. The bagsakan was operationalized and result shows that farmers derived higher profit when they brought their products in the center compared to marketing it to major cities. Other outputs of the project are the trainings conducted but these did not reflect significant contribution to the bagsakan operation. In terms of the relevance of the project, its objective is found valid because it answers to the needs and problems confronting the vegetable farmers. Effectiveness assessment tells that to a little extent the project's objective was attained given the bagsakan's operationalization. Sustainability measurement of the project was not realized since the operation only lasted for one year.
\end{abstract}

Keywords: Trading Center, Vegetable Marketing, Performance Evaluation

http://dx.doi.org/10.21776/ub.agrise.2021.021.3.1

Received 9 March 2021

Accepted 7 July 2021

Available online 31 July 2021

\section{INTRODUCTION}

The conduct of evaluation is a valuable endeavour to assess or measure if government or private funds used to finance development projects resulted to the solution of problems being addressed. Evaluation results are also useful in the design of future programs and projects, to replicate what was found successful and learned from what was not found viable.

The project evaluated is entitled "Supply Chain Management for Fresh Vegetables in Region 10: A Farmer-Cluster Managed 'Bagsakan' Model”. It was under the program: "Supply Chain Management of Selected AFNR Commodities in the Philippines" funded by DOST-PCAARRD and implemented by Central Mindanao University. The project envisioned to make a difference in the lives of the vegetable farmers through capacitating and empowering them to manage their own bagsakan center.

The project's concept was devised from the result of the Phase I study entitled: "Supply Chain Improvement for Fresh Vegetables in Region 10: Phase I". This intervention project is the Phase II level of the program mentioned above. The project's concept was formulated based on the recommendations made in the Phase I study. Vegetable farmers experienced a number of issues and concerns in trading their vegetable produce in the huge bagsakan in Cagayan de Oro City such as being left at the mercy of the middlemen trading in the area. Farmer's managing their own trading center for their products was found an alternative solution to the problems identified.

CITATION: Cosrojas, K., D., J., (2021). Performance Evaluation of the Vegetable Trading Center in Lantapan, Bukidnon, Philippines, Agricultural Socio-Economics Journal, 21(3), 165-174 DOI: 
The project was implemented from 20092011. It was implemented in the non-operational bagsakan center in barangay Kibangay, Lantapan Bukidnon.

The primordial intention of this evaluation was to assess the performance of the project: "Farmer-Cluster Managed Bagsakan Center in Lantapan, Bukidnon". Specifically, it aimed to:

1.Ascertain project activities, implementation and outcomes through the CIPP (context, input, process and product) framework.

2. Assess the project using some of the evaluation criteria by OECD-DAC such as relevance, effectiveness, and sustainability.

3. Identify the lesson's learned of the project for future replication.

Results of the evaluation are valuable input for future similar endevor.

\section{RESEARCH METHODS}

\section{Evaluation Design and Framework}

The study adopted a process evaluation design using primarily qualitative methods. This design will answer the descriptive and normative questions of the project.

The pilot-testing of the bagsakan center in Lantapan, Bukidnon explored the possibility of the small farmers themselves managing the trading center. It envisioned in providing a strategic venue where the good quality vegetables are traded at fair prices with each other. In this manner, profitability of vegetable production would be improved and thereby improving the welfare of the farmers. The project also sought to minimize transaction costs and in turn improve efficiency of the vegetable supply chain. Further, it aimed to provide an opportunity for the cluster members to link themselves directly to the preferred buyers and received the right and fair prices for their products. Moreover, the proposed model aimed to eventually empower the farmers to respond to the requirements of the modern market in terms of volume, quality, and preferred time of delivery and reliability of supply.

Figure 1 shows the evaluation framework of the study. The project performance was examined using the four dimensions as: context, input, process and output. The context evaluation provides basis for determination of the objectives, and defines relevant environment of the project among others. Input assessment provides information on how resources are used, assess capabilities of responsible agency, and assess strategies for achieving objectives. Process dimension detect defects in procedure design or its implementation. Lastly, product evaluation provides measurement and interpretation of project attainments. The investigation of these dimensions will support the over-all project evaluation of whether the intended outcomes were achieved. The result of the assessment of these dimensions is the basis for verifying other evaluation criteria such as relevance, effectiveness, and sustainability. The study of these elements are the basis for confirming the project's performance.

Relevance measures the extent to which the aid activity is suited to the priorities and policies of the target group and recipient. Effectiveness measures the extent to which an aid activity attains its objectives. Finally, sustainability dimension is concerned with measuring whether the benefits of an activity are likely to continue after donor funding has been withdrawn.

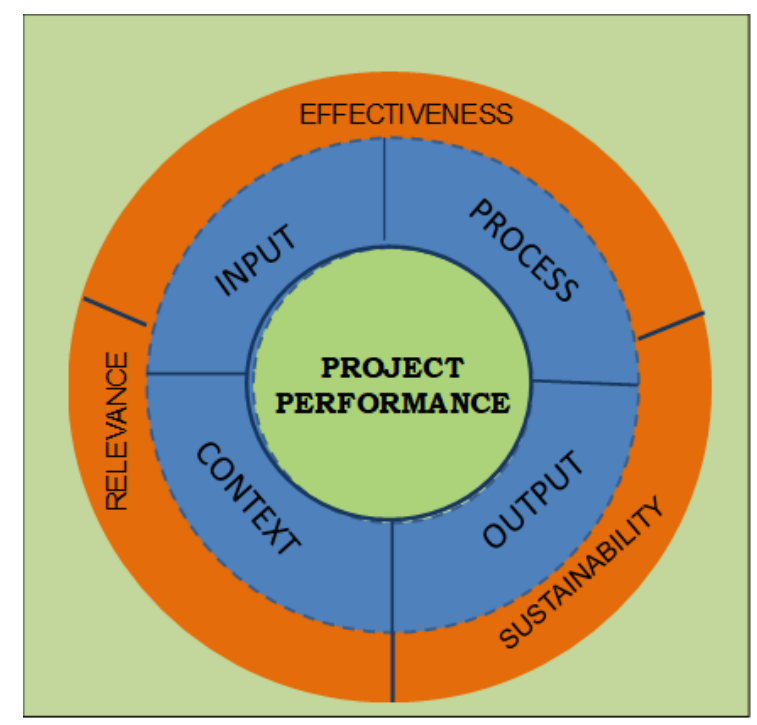

Figure 1. Evaluation Framework of the Study.

\section{Data Collection Methods}

This evaluation study employed both secondary and primary data collection.

The study investigated the project's terminal report and process documentation to 
answer objective number 1 which deals with the project activities, implementation and direct outcomes. Qualitative meta-synthesis was employed specifically the narrative synthesis approach. Meta-synthesis is developed as a research method to interpret research on the same or similar phenomena to contribute to the development of knowledge. Outcome of metasynthesis will contribute to a common understanding of a specific phenomenon. Moreover, findings for this objective were outlined using the CIPP model of evaluation. Qualitative approach was used based on analysis on the results found in the reports.

The second objective which deals on the evaluation criteria set by OECD-DAC was attained using both the secondary source and primary through an interview with the project staff and research collaborators of the implementing agency- Central Mindanao University. The OECD-DAC provided guide questions to answer the dimensions on relevance, effectiveness and sustainability. The same questions were asked to the project staff and research collaborators and results were summarized.

\section{RESULTS AND DISCUSSION}

Objective 1. Project implementation, activities, and direct outcomes

\section{Context Evaluation}

Lantapan, Bukidnon is tagged as the "vegetable basket" of Bukidnon. Majority of the population in the said municipality depend much on vegetable farming as their source of livelihood and way of life as well. The Phase I study of the program mentioned earlier has identified a number of gaps, issues and concerns affecting the supply chain members in Northern Mindanao. In general, the study revealed that the vegetable industry, particularly cabbage and lettuce production has remained inefficient and has been experiencing relatively low performance in terms of income generation due to inefficiencies observed along the chain (Soliven et.al, 2008). Moreover, distribution of income among the supply chain players is not equitable since the traders are still in control of the total vegetable market.
The identified problems in Phase I happen simply because the vegetable farmers are generally incapacitated. Acting individually, they are weak and therefore left at the mercy of the traders during the marketing stage. Moreover, due to insufficient knowledge, they could not respond to the requirements imposed by the modern markets in terms of volume, product quality and timing of delivery, among others.

SCM Phase I results also revealed that there are six (6) existing bagsakan centers in Region 10. Three of these are found in the province of Bukidnon specifically, one each in Lantapan, Manolo Fortich and Impasug-ong. All these are found not functioning and have not been serving their intended purpose. It is in this context where intervention project through a farmercluster managed bagsakan model was conceptualized.

The farmer-cluster managed bagsakan model was probably applicable in finding solutions to the problems identified in vegetable supply chain. It sought to establish a common and strategic area where direct transaction of farmers and traders occur.

\section{$\underline{\text { Input Evaluation }}$}

This determines whether the implementation plan and design correspond to the project goals and objectives.

The project's implementation design was to pilot-test a farmer-cluster managed bagsakan center. Figure 2 shows the project's original conceptual plan or framework. To address the problems and issues confronting the vegetable industry, there was a need for participatory and concerted efforts among the chain players.

ISSU. On top of the farmer clusters, vegetable traders and the "bagsakan" center was the Integrated Support Services Unit (ISSU), which was tasked to facilitate and ensure the sustained operation of the modeled "bagsakan" center.

The ISSU was composed of the representatives from DTI-Bukidnon (Department of Trade and Industry), CMU research team, and the LGU- Lantapan under which are representatives from the offices of the Municipal Agriculture, Planning and Development, 
Treasurer, Engineering, and Accounting. Prior to the partnership, the project leader coordinated with the head of these agencies and explained the project. The heads agreed and signified their commitments to become partners for development through the Memorandum of Agreement signed by them.

Roles of the member-agencies are to organize and cluster farmers; provide trainings to the farmers, share information, technologies and other needs relevant to their farming activities; conduct lakbay-aral/field trip to successful vegetable farms and bagsakan centers as found necessary; and develop a phase-out strategy to ensure that the farmer cluster managed "bagsakan" center will become self-sustaining.

Among the roles of the LGU-Lantapan include: cooperate in the implementation of the vegetable "bagsakan" project; provide assistance in terms of personnel in meeting, organizing and clustering of farmers; provide/share financial and other forms of assistance (i.e. food/snacks and refurbishment of the MPBC) and logistics during the conduct of trainings and lakbay-aral; help in the information drive for other farmers to deliver their vegetables/produce in the MPBC as well as assist in establishing market linkages as possible outlets for their products; give full support to the cluster officers and the committees created who will be directly involved in the day to day operation of the MPBC; and help ensure the sustainability of the project.

The roles of the DTI-Bukidnon are: work closely and conduct regular monitoring of the activities of the MPBC to check whether they are performing in accordance with what is expected of them; disseminate all relevant farm and market information to MPBC and other members of the supply chain; always check on issues/problems and concerns to ascertain that the vegetable farmers and traders are maintaining good business relationship; and link with parties on marketing aspect in the form of trade fair participations, supplier-exporter market encounters and other type of market linkages.

Farmer Clusters. Farmer clusters are small group of individual farmers, who, under a shared agro-enterprise plan, commit to work together for collective marketing.
Traders. The prime purpose of the center was to draw traders in, with the presence of varied types of vegetables offered, good quality and fairpriced tradable serving as a come-on.

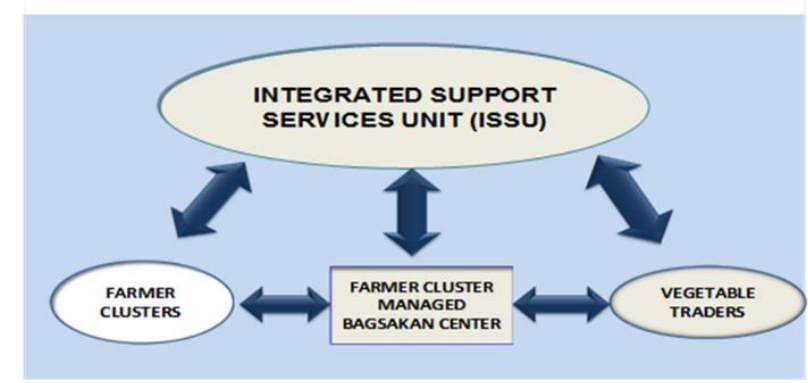

Figure 2. Project's original conceptual framework. (Source: Project's Terminal Report)

After nine months of the project's implementation in Kibangay, Lantapan Bukidnon, the idle bagsakan was found not strategically located since it is $48 \mathrm{~km}$ from the national highway and having a poor road condition. And since, there was an on-going construction of a packaging center located in barangay Poblacion, the project team opted to and as suggested by the LGU to transfer the project implementation in the latter.

The project's transfer necessitated to come up with the new organizational structure for the project implementation. The name also of the center was changed to Municipal Packaging/Bagsakan Center (MPBC) from the original farmer-cluster managed bagsakan center. Figure 3 shows the modified structure. In the new structure, the LGU particularly the municipal mayor and the Sangguniang Bayan play a significant role in the operation. This deflects the original plan of having an independent farmer cluster operating the bagsakan but they are still part of the picture. The farmer cluster federation is to be created in order to have a strong association among the different clusters.

The project's implementation plan adjusted to the needs and findings that were found out along the way. This deflects the original plan but it was being pursued because that was the option available and suited during the time. 


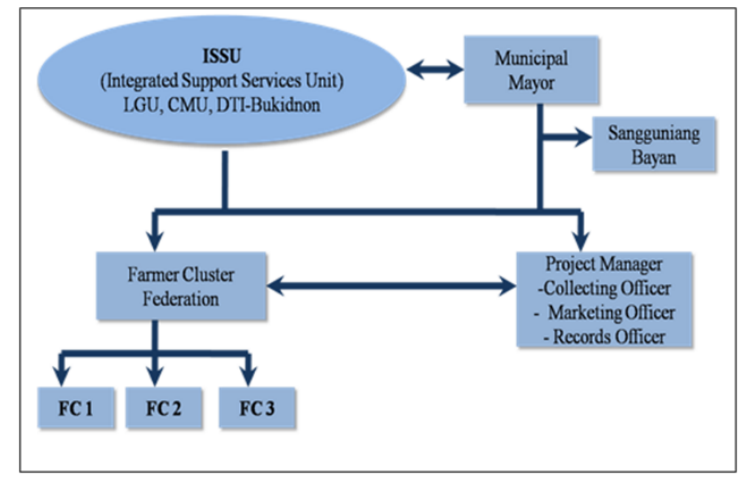

Figure 3. Modified Organizational Structure for the Municipal Packaging/Bagsakan Center. (Source: Project's Terminal Report)

\section{Process Evaluation}

This assesses if the project activities were implemented as planned.

In finding out if the activities were implemented as planned, outputs of the program were summarized vis-a-vi the target. The following are the activities:

1. Industry-wide consultations among the chain players

Before the conduct of the intervention activities, proper protocol was observed by meeting the LGU officials and vegetable farmers. With the primary aim of optimizing the use of resources and to properly address the cited problems in the Phase I study of the supply chain, industry wide consultations through fora and FGDs were made among the chain players. This was to properly design the intervention in terms of identifying the actual and specific needs of the chain players as to the kind of trainings to be conducted, technology to be shared, value formation, and other needs for empowerment.

\section{Creation of the ISSU}

Collaboration with other agencies are imperative to aid in the planning and implementation of activities. The Local Government Units and government agencies mandated to carry out development in the localities were tapped as partners and composed the project's Integrated Support Services Units (ISSU).

The ISSU worked as one in the planning, implementation and addressing of concerns of the intervention project. Meetings have been conducted on the conduct of multi-stakeholders vegetable forum and lakbay-aral. Division of labors among the member agencies was contributory to the success of each activity. Formulation of the Operational Guidelines of the Bagsakan. The unit worked closely through the series of meetings conducted in the formulation of the MPBC's proposed operational guidelines and preparation of the municipal ordinance. The operational guidelines contain the procedures and provisions in the bagsakan operation. Each item in the proposed operational guidelines were thoroughly discussed and reviewed by members of the ISSU until they came up with the final output. The municipal ordinance on the other hand is an order to be issued by the municipality through the Sangguniang Bayan for the institutional operation of the Bagsakan.

\section{Farmer Cluster formation}

To capacitate the weak and less informed vegetable farmers, they have to be well organized into an effective production unit and eventually become responsive to the needs of the modern market. Putting farmers at the center is a strategy that is easier said than done. The usual problem arises from the fact that farmers are not involved in the process, or are treated as second-class participants in a grand plan (business.inquirer.net). The intervention project explored the possibility of the farmers managing their own bagsakan center. Clustering, or the system of grouping farmers to focus on an activity was the approach used in the intervention project.

\section{Farmer clustering on the transfer of the project} site

The transfer of the project to Poblacion, Lantapan called for the need to organize farmer clusters from other vegetable producing barangays in the municipality.

The Municipal Agriculture and Fishery Council (MAFC) is the counterpart of the National Agriculture and Fishery Council (NAFC) in the municipalities. It composed of the Barangay Agriculture and Fishery Council (BAFC) and in charge of supervising and monitoring development projects in the municipalities. The MAFC was tapped to form the farmer clusters in other barangays of Lantapan other than Kibangay since, the MPBC covered the whole municipality. 


\section{Project Orientation in Other Barangays}

There were still farmers in other barangays of the municipality who were not informed of the project and agricultural technicians themselves admitted that they cannot fully impart to them the details of the project. It was in this vein that the team scheduled the farmers clustering and orientation re: operation of the MPBC to the different barangays. The CMU project team oriented the farmers of Kulasihan, Kaatu-an, Songco, and Alanib, Lantapan. It was being explained to the farmers the rationale of the project and the benefits of clustering among others. The team also answered their queries and doubts on the bagsakan operation.

\section{Capability Building}

Based on the consolidated results of the consultations conducted, various kinds of training modules were prepared to suit the needs of the vegetable clusters. There were four (4) trainings conducted on technology and behavior interventions to name: 1) Seminar-Workshop on Farm Accounting; 2) Training on Values Education and Marketing Strategies for Farmers.; 3) Training on Vermi-composting and VermiCulture and Insect Pest Management; 4) Training on Post-Harvest Handling of Vegetables.

In addition to the trainings and seminars conducted to enhance the capability and entrepreneurial skills development of the farmers, the multi-stakeholders vegetable forum was organized with a primary purpose of providing a venue for farmers to know about agricultural technology, production, marketing, success stories of farmers, windows for financial opportunities as well as info-drive of the future operation of the bagsakan in Lantapan.

\section{Lakbay-aral and Field Trips}

To expose the farmers and derive new insights from successful vegetable growers, lakbay aral and field trips are also necessary tools to empower them. Awareness of the recent development in agriculture and sharing of experiences by successful farmers can give new hopes to the less fortunate vegetable farmers. Farmers were brought to successful farms responsive to the needs of the modern market. This gave an opportunity for the poor vegetables farmers to be exposed and gain new insights and learn from the good experiences of successful farmer entrepreneurs. To gain more insights in the formulation of the operational guidelines of the Municipal Packaging/Bagsakan Center (MPBC) in Lantapan, the CMU research team together with representatives of the LGU found it imperative to observe and experience the best practices of successful bagsakan center in some other areas. The group visited and observed the operations of the Sentrong Pamilihan ng Produktong Agrikultura ng Quezon Foundation Inc. (SPPAQFI) in Sariaya, Quezon. The group incorporated in the operational guidelines some of the practices implemented by the foundation such the minimum of the ten kilos packaging of vegetables and the use of the delivery forms and the like.

The proposed operational guideline was submitted to the Sangguniang Bayan (SB) of Lantapan for the crafting of the municipal ordinance. However, the municipal ordinance was not realized until the project has terminated despite the follow-ups and coordination with the head of committee at the SB.

The very core of the intervention project was to see the Bagsakan Center operating with the farmer's products available for sale and cater to the requirements of the buyers. Despite the doubts expressed by some in the possibility of the operation the group pushed for the goal. A number of meetings have been conducted for this purpose. Hence, the regular operation started on August 18, 2011 and went on during Thursdays every week.

\section{Product Evaluation}

This part assessed if the project's output led to significant benefits.

The project has the following expected outcomes:

1. Empowered vegetable farmer clusters operating as a sustainable independent vegetable production and trading unit linked to the right buyers and getting fair share of the industry's profits.

2. Vegetable farmer clusters adopting good farming practices and post-harvest protocols and other farm management strategies to improve profitability levels.

3. Institutionalized Integrated Support Services Unit (ISSU) as board of advisers 
and coordinating unit for all the supply chain members.

4. Vegetable farmers with enhanced market awareness and exposure to good farming practices and environmentally friendly agricultural technologies.

5. Sustainable "Bagsakan" Center as a onestop-information-shop showcasing high quality vegetables with fair prices, reliable volume, quality and efficient time of delivery.

The ultimate goal of the project was to operationalize the bagsakan center and this was realized. However, at the onset it deflects the original plan of making it a farmer-cluster managed center. The bagsakan center operated starting August 2011.

Table 1 shows the operation indicators of the center. As can be gleaned in the table, the number of farmers participating, number of types of vegetables, volume of vegetables and total sales increased with the succeeding operations. In the week 4 to 6 operations more and more buyers other than the LGU and CMU are coming in the center to procure their vegetable requirements. These buyers are characterized as wholesalers, retailers in public markets and owners of food chains. The LGU and CMU also continued to find more buyers especially the institutional ones where the farmers can possibly arrange for a marketing contract.

Table 1. Operation indicators of the municipal bagsakan, Poblacion, Lantapan Bukidnon, August 18-October 5, 2011.

\begin{tabular}{|lcccr|}
\hline Operation & $\begin{array}{l}\text { No. of } \\
\text { Farmers }\end{array}$ & $\begin{array}{l}\text { No. of } \\
\text { Types of } \\
\text { Vegetables }\end{array}$ & $\begin{array}{l}\text { Volume of } \\
\text { Vegetables(Kg) }\end{array}$ & \multicolumn{1}{l|}{$\begin{array}{l}\text { Total } \\
\text { Sales }\end{array}$} \\
\hline Week 1 & 5 & 4 & 265 & $3,948.00$ \\
Week 2 & 4 & 4 & 208 & $4,387.00$ \\
Week 3 & 10 & 13 & 921 & $11,685.25$ \\
Week 4 & 11 & 10 & 872 & $12,621.00$ \\
Week 5 & 16 & 15 & 898 & $17,887.00$ \\
Week 6 & 21 & 17 & 941 & $25,310.00$ \\
\hline
\end{tabular}

Source: Project's Terminal Report

After almost nine months of the bagsakan operation, the research team conducted a survey (May 7-18, 2012) to measure the improvement of the chain performance of vegetables with the MPBC intervention. Survey questionnaire was given to randomly selected four (4) traders and fifteen (15) farmers.

\section{Objective 2. Some OECD-DAC Criteria}

The OECD-DAC criteria in evaluating the project is another way of assessing the project performance using different dimensions and indicators.

\section{Relevance}

Relevance explains the extent to which the aid activity is suited to the priorities and policies of the recipient. The concept of a farmer cluster-managed bagsakan center was anchored from the result of the Phase I study on supply chain of vegetables where problems and constraints confronting the chain were identified. Thus, there is a sufficient basis of its implementation.

Lantapan is the top vegetable producer in the Bukidnon. Farmers usually market their products in Cagayan de Oro and Davao City which incurred higher transportation and transaction costs on their part thus, lessen their profit. The idea of putting up an area where farmers could bring and market their produce is suitable. The project's objective of pilot-testing a bagsakan center is to a great extent valid.

The project implemented activities that are vital to the attainment of the goal of running a bagsakan. However, adjustments were made along the way as some of the activities are not found suitable. This happened when after nine months of the project implementation, the project site was changed from Kibangay to Poblacion. The later was found more strategic as it was nearer to the national highway. The bagsakan in Barangay Poblacion was operationalized but it deflects the original plan of making it a farmercluster managed because it was under the supervision of the LGU-Lantapan. Thus, the output of the project was not consistent with the overall goal and attainment of its objectives.

Meanwhile, to some extent with the operationalization of the bagsakan, farmers who marketed their products in the bagsakan derived higher income compared with bringing their products in Cagayan de Oro and this was evident by the comparative cost and return analysis presented. 


\section{Effectiveness}

This criterion measures the extent to which an aid activity attains its objectives.

Through the effort done by the project implementers and the LGU, the bagsakan was operationalized. However, it deflects the original plan of making it a farmer-cluster managed bagsakan center. The farmer clusters were formed but they were not yet strong enough to operate the bagsakan on their own. The LGU has the manpower and the finances to make possible the operation of the trading center. Nonetheless, it was still made part of the plan that eventually the bagsakan's operation will be turned over to the farmer clusters. To some extent the objectives of the project was achieved.

The consistent effort of the CMU research team to urge the LGU for the operation of the trading center was a huge factor in its operation. The commitment and dedication to the attainment of the goals of the project was found a huge element to achieving the goal.

The project's original implementation was for 2 years (July 2009 to July 2011) and the bagsakan started operating in August 2011. For the CMU team to continually monitor and assist the operation, they initiated a 1-year extension activity under the College of Agriculture where every week they visited the trading center, continued with the farmer clustering and arrange with traders to trade to the bagsakan among others. These activities of the team are significant contributions to the 1-year operation of the trading center.

Meanwhile, time is found to be a factor for the non-achievement of the goal of making it a farmer-cluster managed bagsakan center at the onset of operation. The same with the experiences of successful bagsakan center in other areas, it was anticipated that the trading center will also have its intricate beginnings and one of those is to produce an empowered farmer clusters.

\section{Sustainability}

Sustainability is concerned with measuring whether the benefits of an activity are likely to continue after funding has been withdrawn.

The operation of the bagsakan lasted only for a year. When the one-year extension project of the CMU team ended, the operation also stopped.
The LGU officials did not pursue with the operation because of the lack of funds to finance the needs of the center such as the procurement of the unsold vegetables. The municipal ordinance institutionalizing the operation of the bagsakan which was being agreed upon to be pushed through at the start of the project was not realized. Thus, the bagsakan operation and its sustainability relied much on the will and effort of the LGU.

\section{CONCLUSION}

The project performance was evaluated using the different dimensions outlined below.

In context, the creation of the project was based on the findings identified in the Phase I study of the program thus, its implementation was found suitable to the needs of the vegetable farmers in the municipality.

In the input evaluation, the project implemented a set of strategies and activities to attain its objectives. There have been adjustments made in respond to the needs of the project and this redirect the project to its original plan. This happened when the project site was transferred from barangay Kibangay to barangay Poblacion that necessitated tocome up with the new implementation framework.

For the process evaluation, the activities were implemented as planned however, expected outcomes were not attained as anticipated. For instance, capability trainings were conducted to the farmers in Kibangay but those somehow became useless when the project was transferred to Poblacion.

The product evaluation assessed if the project's output led to significant benefits. The bagsakan was made to operationalize and result shows that farmers derived higher profit when they brought their products in the center compared with marketing it to Cagayan de Oro. Other outputs of the project are the trainings conducted but these did not reflect significant contribution to the bagsakan operation.

In terms of relevance, the project's objective is found valid such that it answers to the needs and problems confronting the vegetable farmers. Moreover, the activities of the project are not found consistent with the overall goal and the attainment of its objectives. 
Effectiveness assessment tells that to a little extent the project's objective was attained given the bagsakan's operationalization but this was not consistent with the original plan of making it a farmer-cluster managed because at the onset, the LGU managed the center.

Sustainability measurement of the project was not found since the operation only lasted for 1 year. It ceased when CMU ceased their extension works and the LGU did not allotted additional amount for the financial transactions in the center.

Lessons learned in the project included issues on partnership, farmer clusters and changing or reversing the usual or traditional trading of vegetables. These are also the factors found to affect the success and sustainability of the project.

\section{ACKNOWLEDGEMENTS}

The author would like to mention the DOSTPCAARRD for funding the project and to the CMU project team headed by Dr. Maria Luisa R. Soliven together with Prof. Sheila C. Poonon, Prof. Mahalia
M. Acuna, Dr. Maria Emily S. Damag, Dr. Annie L. Deriada, Prof. Perla L. Bugayong, and Dr. Lydia Sison. Special mention and gratitude to Engr. Charlita Escano for the concept and input of the study.

\section{REFERENCES}

Horton, D.C. (1997). Disciplinary Roots and Branches of Evaluation: Some Lessons from Agricultural Research. Discussion Paper. No. 96-7. April 16, 1997. The Hague Netherlands: International Service for National Agricultural Research (ISNAR).

Soliven, M.L., Poonon, S.C., Acuna, M.M., Bugayong, P., Damag, M.S., Deriada, A.L., Sison, L. Supply Chain Improvement for Fresh Vegetables in Region 10: A Farmer-Cluster Managed "Bagsakan" Model. Terminal Report. (2011). Terminal Report. Unpublished.

Suvedi, M. (1988). Introduction to Program Evaluation. Department of Agricultural and Extension Education. Michigan State University.

Suvedi, M. \& Shawn Morford. (Undated). Conducting Program and Project Evaluations. A Primer for Natural Resource Program Managers. FORREX. British Columbia. 
This page is intentionally left blank 